\title{
Epidemiological \& Clinical Profile of Patients Presented with Mandible Fracture in a Tertiary Care Hospital
}

\author{
F SULTANA $^{\mathrm{a}}$, MR KARIM ${ }^{\mathrm{b}}$, IA HAIDER ${ }^{\mathrm{c}}$
}

\begin{abstract}
Summary:
Mandible is the second most commonly fractured bone after nasal bone, though it is the largest and strongest facial bone. Fractures of the mandible can involve only one site or can often involve multiple anatomic sites. It account for $36 \%$ to $59 \%$ of all maxillofacial fracture. The large variability in reported prevalence is due to a variety of contributing factors such as gender, age, environment, and socio-economic status of patient, as well as the mechanism of the injury. The most favorable site of fracture (in descending order) in mandible is the body, angle, condylar region, symphysis, and coronoid process.

The descriptive type of cross sectional retrospective study was undertaken to determine the epidemiological \& clinical profile of patients presented with fractures of mandible and their different methods of treatment modalities. Four hundred and thirty five patients with mandible fractures were treated during the year 2014-2015. A review of patient's record was conducted. Data regarding age, gender, cause of fracture, anatomic site and treatment modalities were reviewed. There was higher prevalence in male (3.9:1), with occurrence peak between 21-30 years. The principal causes of fracture in this study were RTA (Road Traffic Accidents) representing $54.02 \%$ followed by
\end{abstract}

\section{Introduction:}

The mandible is the area of the face with major incidence of fracture. Its prominence and position in the skeletal face predispose to frequent traumas ${ }^{1}$. Mandible is the second most commonly fractured bone after nasal bone, though it is the largest and strongest facial bone. Mandible fractures can involve only one

a. Dr. Farjana Sultana, Assistant Professor, Department of Oral and Maxillofacial Surgery, Dhaka Dental College, Dhaka.

b. Dr. Md. Rezaul Karim, Assistant Professor, Department of Oral and Maxillofacial Surgery, Colonel Malek Medical College, Manikgong.

c. Professor Dr. Ismat Ara Haider, Head, Department of Oral and Maxillofacial Surgery, Dhaka Dental College and Hospital

Address of Correspondence: Dr.Farjana Sultana, Assistant Professor, Department of Oral and Maxillofacial Surgery, Dhaka Dental College, Dhaka.E-mail: sultanaf19@yahoo.com

Received: 15 Nov. 2017

Accepted: 7 April 2018 physical assault 17.24\%, Fall, Sports injury, Blow by heavy objects, Tube well injury \& others which includes Tire blast injury, Gunshot injury, Iatrogenic cause, Pathological fracture, Boat handle injury, Penetrating injury by metal etc. The most injured sites were in parasymphysis (26.31\%) followed by angle of mandible $17.89 \%$ then symphysis, condyle, body of mandible, dentoalveolar, ramus, coronoid process of mandible. Most patients (70.11\%) of mandible fractures were treated by closed reduction (arch bar, arch bars with intermaxillary fixation IMF, eyelet wiring \& lateral compression plate) \& $21.83 \%$ of patients were treated with open reduction (miniplates fixation. $3 D$ plate fixation) .Only $8.05 \%$ patients were managed by conservative approach. This study reflects patterns of mandible fracture within the community and discuss various methods of mandible fracture management in the department of Maxillofacial casualty in Dhaka Dental college hospital. It is hoped that information presented here will be useful to the government agencies and health care professionals involved in planning future programs of prevention \& treatment of mandible fracture.

Key words: Epidemiology, clinical profile of mandible fracture, treatment modalities.

(J Bangladesh Coll Phys Surg 2018; 36: 107-111) DOI: http://dx.doi.org/10.3329/jbcps.v36i3.37034

site or can often involve multiple anatomic sites simultaneously. ${ }^{2}$

The etiology and pattern of mandible fractures vary considerably among different study populations ${ }^{2}$. Recent overall shift in the mechanism of injury and age distribution of patients sustaining these injuries are well-documented. There is reported variability in the pattern of fractures of mandible resulting from different causes of injury, such as road traffic accidents (RTAs), assaults, and falls ${ }^{3,4}$.Increased frequencies of RTA and domestic violence have emerged as the etiological factors in mandible fractures in developing countries like India. Furthermore, there is an increase in the proportion of adolescent and young adults sustaining this injuries. ${ }^{2}$ :

Mandible fractures may lead to deformities be them by displacement or non restored bone losses, with dental occlusion affection or temporomandibular joint 
disorder. If not identified or inappropriately treated, these lesions may lead to severe squeals, both cosmetic and functional. 5,6

It has been reported that fractures of the mandible account for $36 \%$ to $59 \%$ of all maxillofacial fracture. ${ }^{7}$ The large variability in reported prevalence is due to a variety of contributing factors such as gender, age, environment, and socio-economic status of patient, as well as the mechanism of the injury. The most favorable site of fracture (in descending order) in mandible are the body, angle, condylar region, symphysis, and coronoid process. ${ }^{8}$

Treatment of mandible fractures has changed over the last 20 years. There has been a decrease in the use of wire osteosynthesis and intermaxillary fixation and an increase in preference for open reduction and internal fixation with miniplates. ${ }^{9}$ This has helped to reduce malocclusion, non-union, improved mouth opening, speech, oral hygiene, decrease loss and the ability for patients to return to work earlier. ${ }^{9}$

The aim of the study was to see the epidemiology \& clinical profile of mandible facture and different methods of mandible fractures management. A clearer understanding of pattern of mandible fractures will assist health care providers as they plan and manage the treatment of traumatic maxillofacial injuries. Such information can also be used to guide the future funding of public health programmer geared toward prevention $^{8}$

\section{Methodology:}

Descriptive type of retrospective cross sectional study was conducted in the casualty department of Oral and Maxillofacial Surgery of Dhaka Dental College \& Hospital during the year of January2014Decembere2015. The Department of Oral and Maxillofacial Surgery of Dhaka Dental College is the largest centre for facial trauma management in Bangladesh. Among four hundred and thirty five patients with mandible fractures who managed in this department during the year 2014-2015. Epidemiological \& Clinical information were extracted from the case records form which included gender, age, etiology of injury, area of injuries and treatment methods. The mechanism of injury was recorded as Road traffic accident, Physical assault, fall, Sports injury, Blow by heavy objects, Tube well injury \& others. Site of fractures was recorded and methods of management were included.

Data was collected and tabulated by using Microsoft Excel 2007.

\section{Results:}

In the studied period, mandible fractures were diagnosed in 435 patient's data regarding age, gender, cause of fracture, anatomic site and treatment modalities were reviewed. There was higher prevalence in male (3.9:1). (Figure-1)

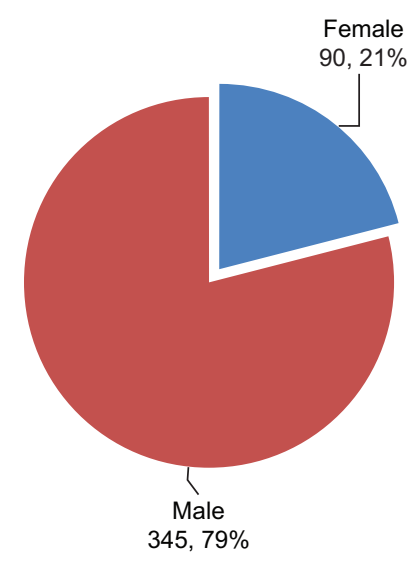

Fig.-1: Gender distribution of the respondents $(n=435)$

Figure illustrates the sex distribution of the respondents. Out of 435 patients $345(79 \%)$ were male and $90(21 \%)$ were female respondents. Male were predominant.

Age incidence was peak between 21-30 years. (Figure-2)

\section{Table-I}

Age distribution of the respondents $(n=435)$

\begin{tabular}{ccc} 
Age (Years) & Frequency & Percentage \\
\hline $0-10$ & 47 & $10.80 \%$ \\
$11-20$ & 87 & $20.00 \%$ \\
$21-30$ & 117 & $26.89 \%$ \\
$31-40$ & 73 & $16.78 \%$ \\
$41-50$ & 50 & $11.49 \%$ \\
$51-60$ & 33 & $7.58 \%$ \\
$61-70$ & 16 & $3.67 \%$ \\
$71-80$ & 12 & $2.75 \%$ \\
\hline Total & 435 & $100 \%$ \\
\hline
\end{tabular}


Figure shows the highest incidence of mandible fracture was in the age group of 21-30 years (26.89\%), followed by the age group of 31-40 (16.4\%).

The principal causes of fracture in this study were RTA (Road Traffic Accidents) representing $54.02 \%(\mathrm{n}=235)$, followed by physical assault $17.24 \%$ $(\mathrm{n}=75)$, Fall from hight, Sports injury, Blow by heavy objects, Tube well injury \& others. (Figure-2)

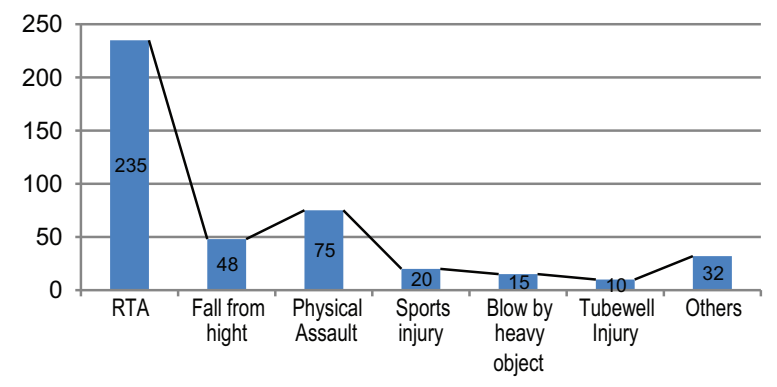

Fig.-2: Distribution of mandible fracture according to etiology $(n=435)$.

Figure shows etiology of mandible fracture. $(n=435)$

The most injured sites were in decreasing order parasymphysis $(26.31 \%)$ followed by angle of mandible $17.89 \%$ then symphysis, condyle, body of mandible dentoalveolar, ramus, coronoid process of mandible (Figure-4).

\section{Table-II}

\section{Anatomical location of mandible fractures}

\begin{tabular}{lcc} 
Site of fractures & Number of patients & Percentage \\
\hline Symphysis & 83 & $17.47 \%$ \\
Parasymphysis & 125 & $26.31 \%$ \\
Dentoalveolar & 45 & $10.34 \%$ \\
Body & 60 & $13.79 \%$ \\
Angle & 85 & $17.89 \%$ \\
Condyle & 65 & $13.68 \%$ \\
Ramus & 9 & $2.06 \%$ \\
Coronoid & 3 & $.68 \%$ \\
\hline Total & 435 & $100 \%$ \\
\hline
\end{tabular}

Figure shows site wise distribution of mandible fractures.

Most patients of mandible fractures were treated by closed reduction (arch bar, arch bars with intermaxillary fixation IMF, eyelet wiring \& lateral compression plate) $70.11 \% \& 21.83 \%$ of patients were treated with open reduction ( miniplates fixation. 3D plate fixation) . Only $8.05 \%$ patients were managed by conservative approach. (Figure-5)

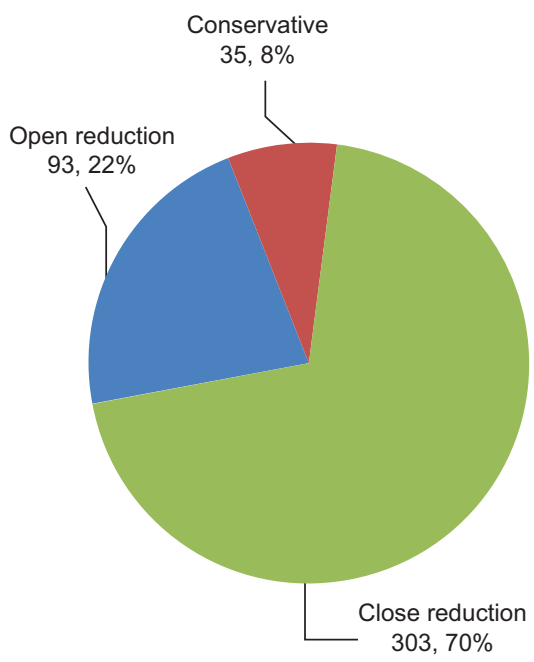

Fig.-3: Treatment of mandible fractures $(n=435)$

Figure shows treatment modalities for mandible fractures.

\section{Discussion:}

All over the world, maxillo-facial injuries have continued to generate discussion among researchers, due to the functional and cosmetic deformities affecting the victims. The etiological factors and pattern of maxillo-facial injuries have been reported to vary from one geographical area to another, depending on the socioeconomic status, geographic condition and cultural characteristics. ${ }^{10}$ Despite the fact that it is the heaviest and strongest facial bone, the mandible is prone to fractures for some specific reason: 1) it is an open arch; 2) it is located in the lower portion of the face; 3 ) it is the mechanism of hyperextension and hyperflection of the head in traffic accidents; 4) it gets atrophy as a result of aging. ${ }^{8}$

The results of this study of mandible fracture coincide with previous reports, particularly regarding age and sex of patients. ${ }^{2}$ In our study, the highest incidence of mandible fractures is found in the age group of 21-30 years $(26.89 \%)$. Age incidence was similar with a study by Amin et $\mathrm{al}^{10}$. The possible reasons for this in our geographic area may be very high use of two-wheelers, early bikers, lack of safety measures in the form of 
helmets and improper road conditions, as most of fractures in this group belong to RTAs. ${ }^{2}$

There was higher prevalence in male (3.9:1), The male predominance observed in our study agrees with data reported in literature around the world, namely a maleto-female ratio of approximately $3: 1 .{ }^{11}$ Males are more exposed, due to their more frequent participation in high risk activities, such as driving vehicles, sports that involve physical contact, an active social life, drugs and alcohol habits, etc. ${ }^{10}$

The principal causes of fracture in this study were RTA (Road Traffic Accidents) representing 54.02\%( $\mathrm{n}=235)$, followed by Physical assault $17.24 \%(\mathrm{n}=75)$, Fall, Sports injury, Blow by heavy objects, Tube well injury \& others. There is a stark difference in the etiology of maxillofacial trauma in developing and developed nations. The common cause of maxillofacial trauma in developing countries is RTAs, while assault is the most common cause in developed countries. Our findings also support the same, as $68 \%$ of our patients; RTA was the cause of injury. ${ }^{2}$ These etiological differences reflect differences in the socioeconomic factors, national infrastructure development (particularly roadways, traffic regulations and legislation) and other behavioral habits, such as alcohol consumption or criminal activities. The high number of maxillo-facial injuries attributed to RTA is explained by inadequate road safety awareness; unsuitable road conditions .2

The most common site of fracture in mandible evidenced by the present investigation was the paramedian one $(26.31 \%)$, which is consistent with the findings of King ${ }^{12}$, who established a statistical significance between road traffic accidents and parasymphysis fractures. Atanasov ${ }^{13}$ and Wong 14 reported that motorcycle accidents (79.5\%) were the major cause of mandible fractures, with the parasymphysis as the most common site. Sunita Malik et al. ${ }^{15}$ also founded parasymphysis as the most common site of fracture in the mandible. hout expansion of motorworks; violation of speed limit; old vehicles without safety features ${ }^{12}$

In present study angle of mandible fractures were second most common $17.89 \%$. However, Olson et al. ${ }^{16}$ showed that there was a higher incidence of angle involvement in patients with mandible trauma. ${ }^{2}$
However, our study was not consistent with the findings of Adekeye ${ }^{17}$, Nair ${ }^{18}$ and Adebayo ${ }^{19}$, who reported the body as the most prominent site, whereas Van Beek ${ }^{20}$ found the condyle as the most common $\operatorname{site}^{11}$ It is difficult to cite a reason for this difference; perhaps further study on the causes of the regional mandible fractures would be useful. One can speculate that interpopulation difference in the sites of mandible fractures partly related to the diverse etiologic factors involved ${ }^{8}$. Several treatments may be applied in maxillofacial fractures, the differences among them depending on many factors, such as costs, patient's affordability, conditions in the hospital, doctor's decision and skill, patient's willingness to obey the treatment - all of them varying from one country to another. The choice of either closed or open approach methods of treatment of mandible fractures depended mainly on availability of resources ${ }^{21}$. Due to absence of facilities of GA at causality department, most of the patients $70.11 \%$ treated from closed reduction with arch bar fixation, and only few of them had open reduction and internal fixation, which is consistent with the studies conducted by Kamulegeya A. ${ }^{22}$, Chandra ${ }^{23}$, Erol et al. ${ }^{24}$, Kilasara et al. ${ }^{25}$ and Sunita Malik et al. ${ }^{15}$. Open reduction and internal fixation has been reported to be the "gold standard" of the treatment of maxillo-facial fractures ${ }^{11}$

In recent years, there has been a trend towards rigid fixation with miniplates. In our study 22 cases $(21.83 \%)$ were treated with miniplates. The postoperative results were satisfactory. Most of the patients belong to low socio-economic status; therefore, limited numbers of cases were selected for miniplate fixation

\section{Conclusions:}

Road traffic accidents (RTA) represented the major etiological factor of maxillo-facial injuries, with young adult males as they are main victims. The high number of trauma victims with maxillofacial injuries evidenced in the present study highlights the importance of the Dental Surgery unit, besides the other disciplines assuring an emergency management of trauma victims. This study also evidences the importance of cooperation and coordination among the various medical disciplines, for a rapid management of maxillo-facial injuries, and not only, which might prevent functional as well as aesthetic morbidity. 


\section{References:}

1 Schaffer M, Rebellato NL, Passeri LA,Primo BT, Moraes RS. Teeth in the line of mandibular fractures: Epidemiology, management and complication. J Maxillofac Traumatology 2013;13:23-30.

2. Barde D, Mudhol A, Madan R. Prevalence and pattern of mandibular fracture in Central India. Nat J Maxillofac Surg 2014; 5(2): $153-156$.

3. Thorn JJ, Møgeltoft M, Hansen PK. Incidence and aetiological pattern of jaw fractures in Greenland. Int J Oral Maxillofac Surg 1986;15:372-9.

4. Scherer M, Sullivan WG, Smith DJ, Jr, Phillips LG, Robson MC. An analysis of 1,423 facial fractures in 788 patients at an urban trauma center. J Trauma1989;29:388-90.

5 Busuito MJ, Smith Jr, Robson MC. Mandibular fractures in an urban trauma center. J Trauma 1986; 26:826-9.

6. Olson B, Fonseca RJ, Zeitler DL, et al. Fractures of the mandible: A review of 580 cases. J Oral Maxillofac Surg 1982; 40:23-8.

7. Brook IM, Wood N. Aetiology and incidence of facial fractures in adults. Int J Oral Surg 1983; 12:193-8.

8. Shah A, Shah AA, Salam A Pattern and management of mandibular fractures: a study conducted on 264 patients .Pakistan Oral \& Dental Journal 2007; 27 (1):103-6.

9. Rix L, Stevenson ARL, Punnia-Moorthy A. An analysis of 80 cases of mandibular fractures treated with miniplates osteosynthesis. Int J Oral Maxillofac Surg 1991; 20:337-41.

10. Amin MR, Chowdhury MAP, Sarwar MG,Moula SM, Kabir MH, Ahmed TI et al. A retrospective study of mandibular fracture in a 2-year period. Bangladesh Dental J 2016;32(1): 1-3.

11. Malik S, Singh G. Incidence, aetiology and pattern of mandible fractures in sonepat, haryana (india). International Journal of Medical Dentistry2014; 4 (1) :51-59.

12. King RE, Scianna JM, Petruzzelli GJ. Mandible fracture patterns: a suburban trauma center experience. Am J Otolaryngol 2004; 25(5):301-7.

13. Atanasov DT. A retrospective study of 3326 mandibular fractures in 2252 patients. Folia Med (Plovdiv) 2003; 45(2): 38-42.
14. Wong KH (2000) Mandible fractures: a 3 year retrospective study of cases seen in an oral surgical unit in Singapore. Singapore Dent J 2000 ;23(1):6-10.

15. Sunita Malik et al. Analysis of maxillofacial trauma at Rohtak( Haryana), India: five years prospective study. Journal of Maxillofacial Trauma 2012;1(2): 43-50.

16. Olson RA, Fonseca RJ, Zeitler DL, Osbon DB. Fractures of the mandible: A review of 580 cases. J Oral Maxillofac Surg. 1982;40:23-8.

17. Adekeye EO. The pattern of the fractures of the facial skeleton in Kaduna, Nigeria: a survey of 1447 cases. Oral Surg. Oral Med. Oral Pathold 1980; 49: 491-5.

18. Nair BK, Paul G.Incidence and aetiology of maxillofacial skeleton in Trivandrum- A retrospective study. Br J Oral Maxillofac Surg1986; 24: 40-43.

19. Adebayo ET, Ajike OS, Adekeye EO. Analysis of the pattern of Maxillofacial fractures in Kaduna,Nigeria. Br J Oral and Maxillofac Surg 2003, 41(6): 396-400,

20. Van Beek GJ, Merkx CA. Changes in the pattern of fractures of the maxillofacial skeleton. Int J Oral maxillofac Surg1999;28(6): 424-428.

21. Amin MR, Chowdhury MAP, Sarwar MG,Moula SM, Kabir MH, Ahmed TI et al. Proportional analysis of developments in the treatment of mandibular fractures .Bangladesh Dental J 2016; 32(2):56-58.

22. Kamulegeya A, Francis L, Kate K. Oral maxillofacial fractures seen at a Ugandan tertiary hospital: a sixmonth prospective study. Clinics 2009; 64: 843-8.

23. Chandra Shekar BR, Reddy C. A five-year retrospective statistical analysis of maxillofacial injuries in patients admitted and treated at two hospitals of Mysore city. Indian J Dent Res 2008; 19: 304-8.

24. Erol B, Tanrikulu R, Gorgun B. Maxillofacial fractures: analysis of demographic distribution and treatment in 2901 patients (25years experience). J Craniomaxillofac Surg 2004; 32: 308-13.

25. Kilasara DB, Mecky IM, Shubi F. Epidemiology and management of maxillofacial fractures treated at Muhimbili National Hospital in Dar es Salaam, Tanzania 1998-2003. International dental journal 2006; 56: 131-134. 